\title{
VIBRATION ANALYSIS OF CENTRIFUGAL BLOWER IMPELLER FOR VARIOUS MATERIALS USING FEA
}

\author{
Adgale Tushar Balkrishna ${ }^{1}$, P.D.Darade ${ }^{2}$, Govind Raiphale ${ }^{3}$ \\ ${ }^{I}$ M.E. Design, Alard College of Engineering \& Management, Pune, India \\ ${ }^{2}$ Asst. Professor, SITS, Narhe Pune, India \\ ${ }^{3}$ M.E. Design, Pune, India
}

\begin{abstract}
It is important to recognize that the design of any machine is an interdisciplinary process, involving aerodynamics, thermodynamics, fluid dynamics, stress analysis, vibration analysis, the selection of materials, and the requirements for manufacturing. The operation of any mechanical system will always produce some vibration. Our goal is to minimize the effect of these vibrations, because while it is undesirable, vibration is unavoidable. The result of excess vibration can vary from nuisance disturbance to a catastrophic failure. All fans must generate some vibration. They continuously rotate and since nothing is perfect, cyclic forces must be generated. It's only when vibration reaches a certain amplitude that we call it bad. Vibration may just be an indicator of some problem with a mechanism, or it may be a cause of other problems. Finally, vibration can transmit into adjacent areas and interfere with precision processes, or create an annoyance for people. Hence the objective of this study is to present vibration analysis of centrifugal blower for materials such as steel, aluminium and composite (glass/epoxy).
\end{abstract}

Keywords - Centrifugal Blower, Impeller, Static, Modal and Harmonic Response, CATIA V5 R19, ANSYS 14.5.7 $* * *$

\section{INTRODUCTION}

Fans and blowers provide air for ventilation and industrial process requirements. Fans generate a pressure to move air (or gases) against a resistance caused by ducts, dampers, or other components in a fan system. The fan rotor receives energy from a rotating shaft and transmits it to the air. Blowers are one of the important component used regularly in Boiler operation. High efficient fans can increase Boiler efficiency. They are used to supply air for combustion of fuel in boiler furnace using Forced Draught (FD) fan, installed in front side of furnace supplying air either at normal temperature or at elevated temperature, if air is supplied using air-pre heater. The fans must have a pressure capability high enough to overcome the total resistance of inlet silencers, air preheat coils, air ducts, air heaters, wind boxes, burner registers, and any other resistance between the air intake of the fan and the furnace. The flue gases generated after combustion of fuel can be drawn out using Induced Draught (ID) fans. They maintain furnace pressure slightly below atmospheric. Primary Air (PA) fans are used to supply combustion air for atomization of pulverized fuel. Secondary Air (SA) fans are used to convey pulverized fuel through duct conveying system. Generally FD, $\mathrm{SA}$, and PA are direct-drive fans whereas ID fan is belt-driven fan.

\section{LOADING CONDITION AND CASE DESCRIPTION}

There are three types of loading that actually act on the centrifugal fan impeller. The first one is the centrifugal force caused because of impeller rotation that results in centrifugal acceleration of the impeller body. The second is that resulted from thermal expansion caused by temperature rising. The last one is the aerodynamic force arising from pressure conversion between the blade and the air.

The impeller considered for case study has OD $660 \mathrm{~mm}$, ID $200 \mathrm{~mm}$, Width of blade at leading edge is $45 \mathrm{~mm}$, Width of blade at trailing edge is $30 \mathrm{~mm}$, thickness of back plate is 6 $\mathrm{mm}$, thickness of blades is $5 \mathrm{~mm}$, and shroud is $4 \mathrm{~mm}$. Number of blades are 12. Rotational speed of impeller is 2900 rpm.

Steps in Project Work

A. Modeling by Using CATIA V5 R19: Modeling of Impeller is done using 3D software CATIA V5 R19. .

B. Meshing and Analysis Using ANSYS14.5.7: Meshing and analysis of centrifugal blower has been carried out by using ANSYS 14.5.7 general purpose FEM software.

C. Material Selection: The materials selected here are generally used for fabrication purpose of blower viz., steel, aluminium and glass/epoxy

\subsection{Steel:}

Material Properties

\begin{tabular}{|l|l|}
\hline Density $\left(\mathrm{kg} / \mathrm{m}^{3}\right)$ & 7850 \\
\hline Yield Strength (Mpa) & 250 \\
\hline Ultimate tensile Strength (Mpa) & 460 \\
\hline Poisson's ratio & 0.3 \\
\hline Young's modulus(Gpa) & 200 \\
\hline Bulk modulus (Gpa) & 167 \\
\hline Shear Modulus (Gpa) & 76.923 \\
\hline
\end{tabular}




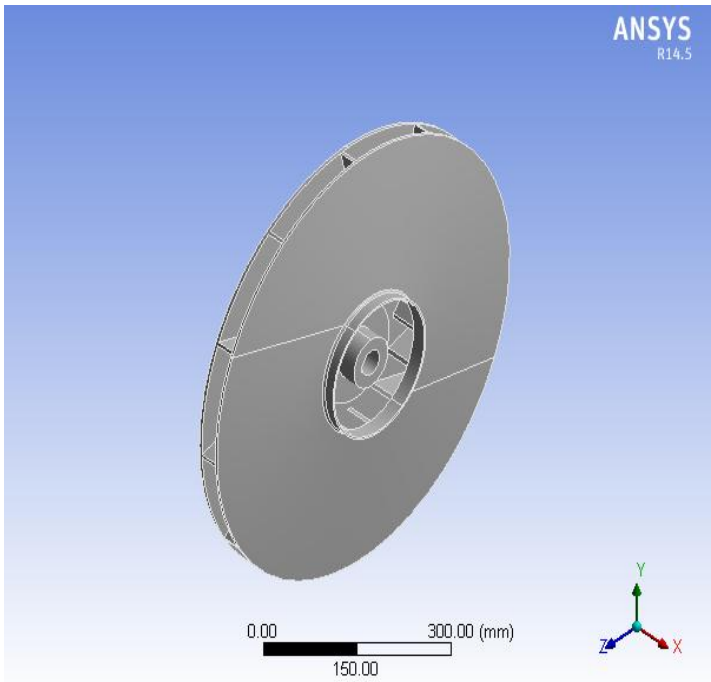

Fig.13D model of blower impeller

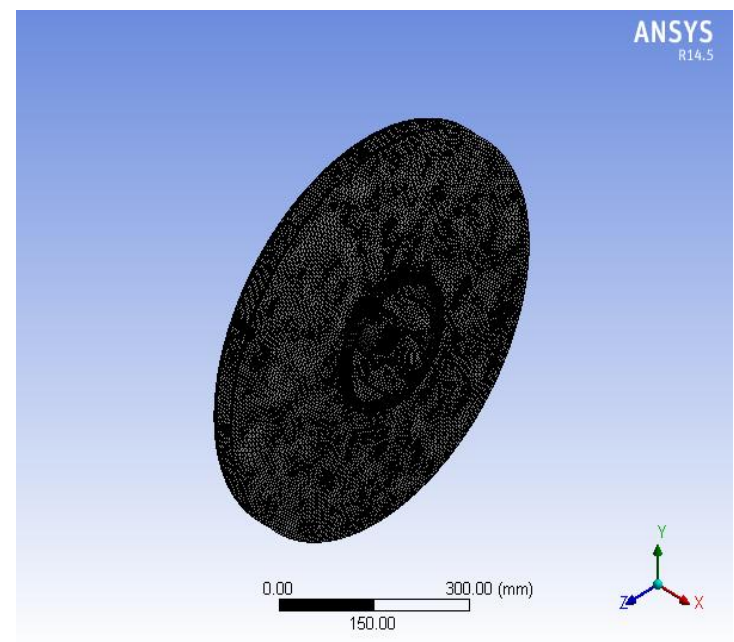

Fig.2 Meshing of blower impeller

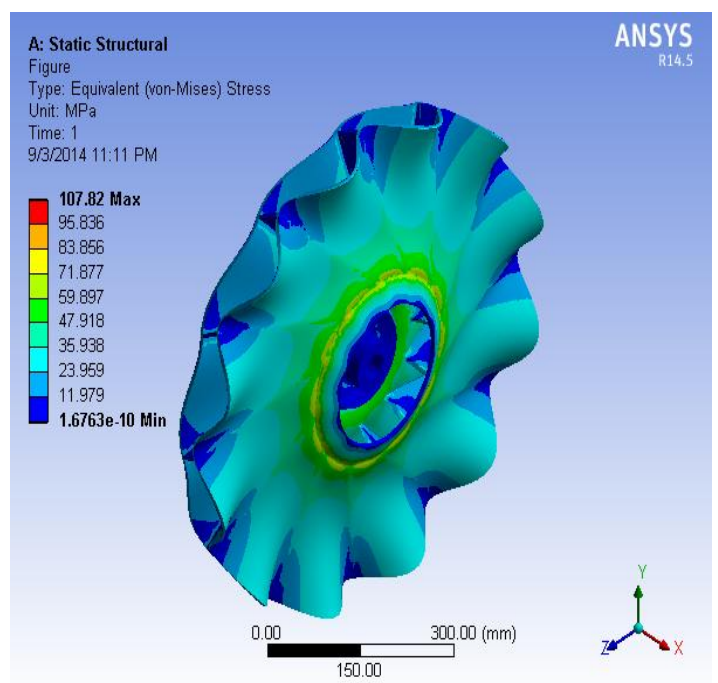

Fig.3 Equivalent (von-mises) stress of blower impeller (steel)

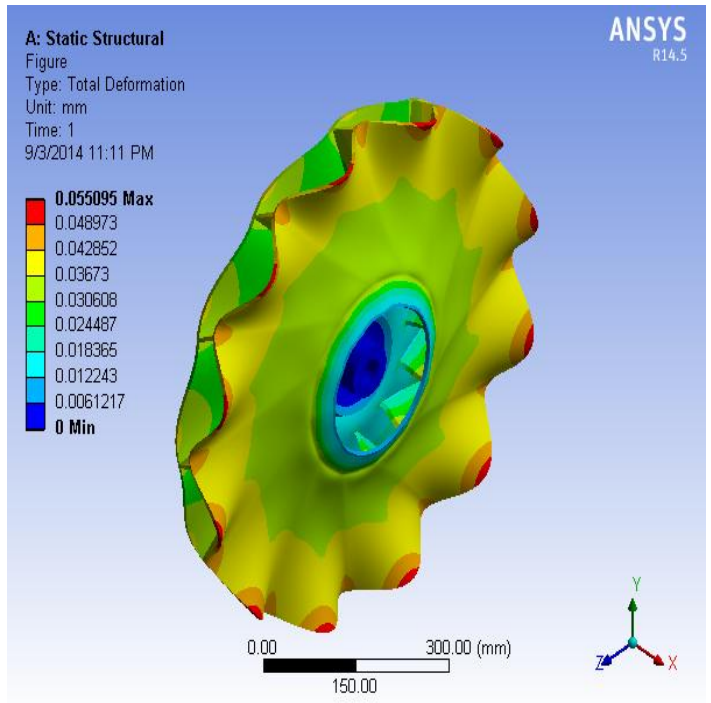

Fig.4 Total deformation of blower impeller (steel)

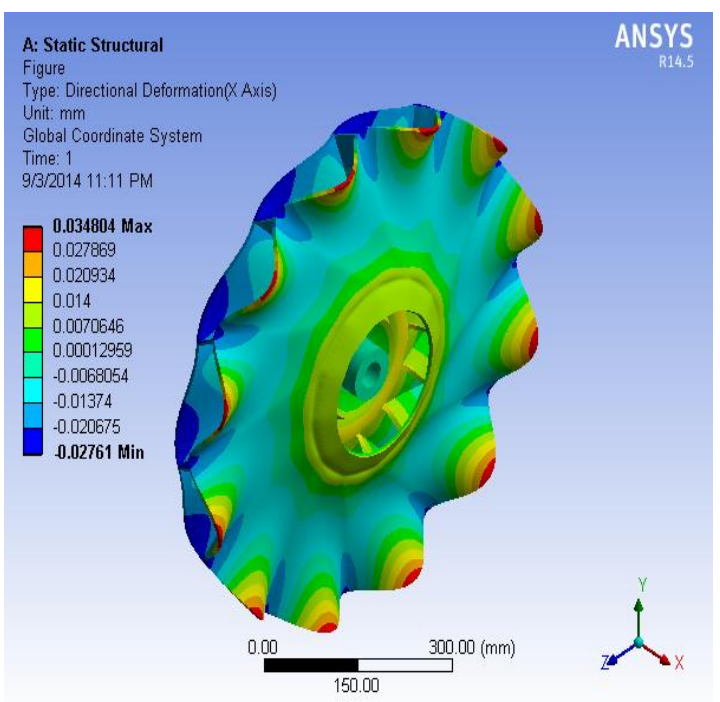

Fig.5 Directional deformation (x-axis) of blower impeller (steel)

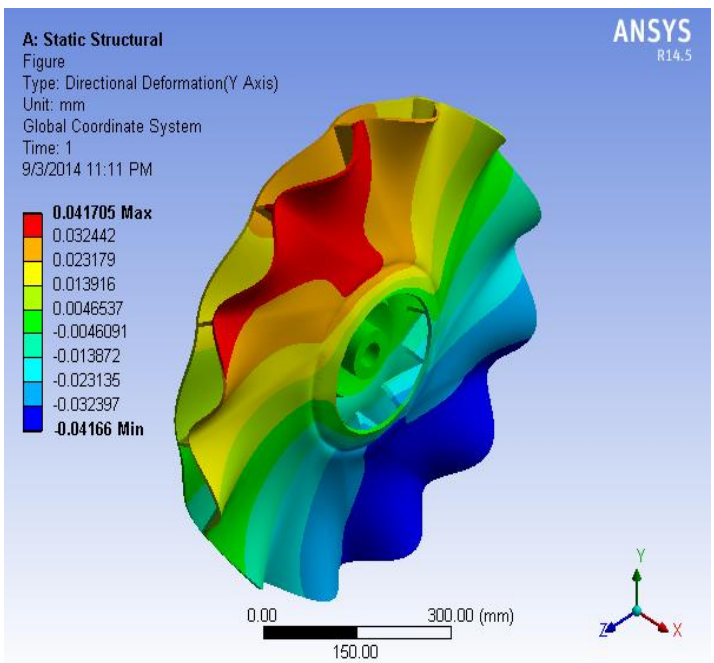

Fig.6 Directional deformation (y-axis) of blower impeller (steel) 


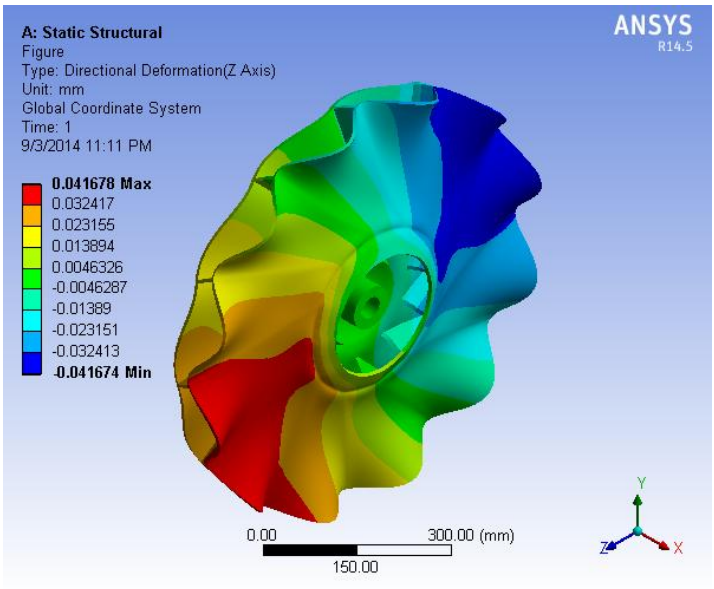

Fig.7 Directional deformation (z-axis) of blower impeller (steel)

\begin{tabular}{|l|l|}
\hline Mode & Frequency $[\mathrm{Hz}]$ \\
\hline 1. & 122.3 \\
\hline 2. & 122.36 \\
\hline 3. & 314.95 \\
\hline 4. & 403.88 \\
\hline 5. & 414.66 \\
\hline 6. & 414.73 \\
\hline 7. & 696.07 \\
\hline
\end{tabular}

Fig.8 Prestressed natural frequency of blower impeller (steel)

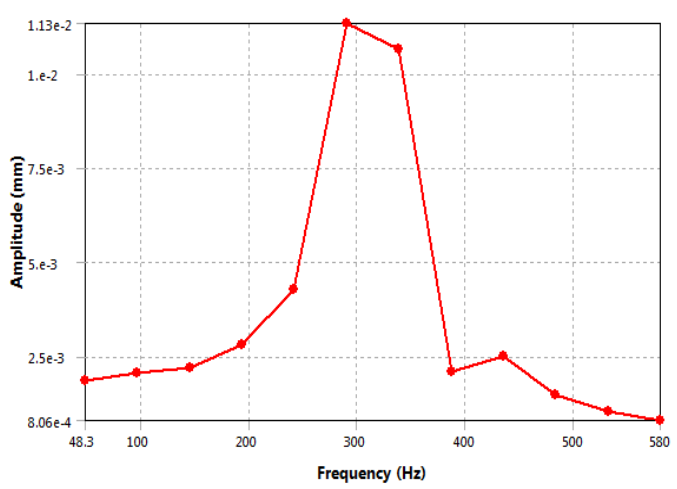

Fig. 9 Deformational Amplitude (x axis) V/s Frequency of steel Impeller

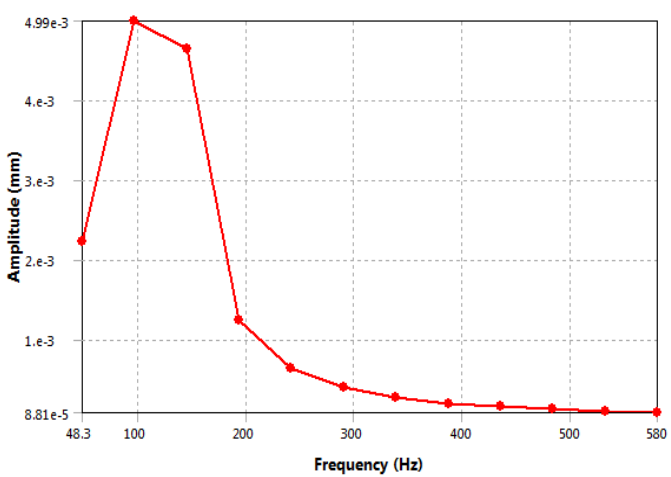

Fig. 10 Deformational Amplitude (y axis) V/s Frequency of steel Impeller

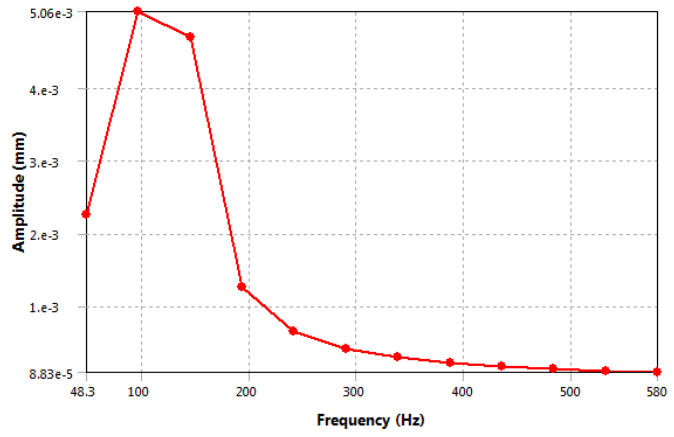

Fig. 11 Deformational Amplitude (z axis) V/s Frequency of steel Impeller

\subsection{Aluminium}

Material Properties

\begin{tabular}{|l|l|}
\hline Density $\left(\mathrm{kg} / \mathrm{m}^{3}\right)$ & 2770 \\
\hline Yield Strength (Mpa) & 280 \\
\hline Ultimate tensile Strength (Mpa) & 310 \\
\hline Poisson's ratio & 0.33 \\
\hline Young's modulus(Gpa) & 71 \\
\hline Bulk modulus (Gpa) & 69.61 \\
\hline Shear Modulus (Gpa) & 26.7 \\
\hline
\end{tabular}

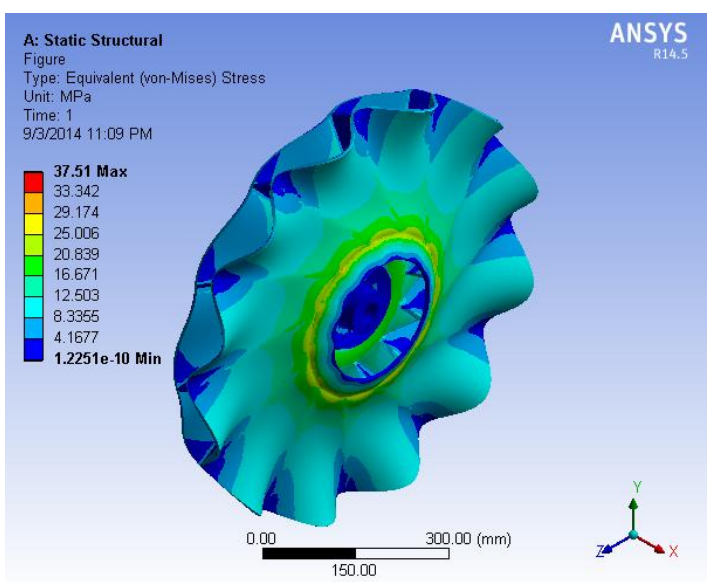

Fig.12 Equivalent (von-mises) stress of blower impeller (aluminium)

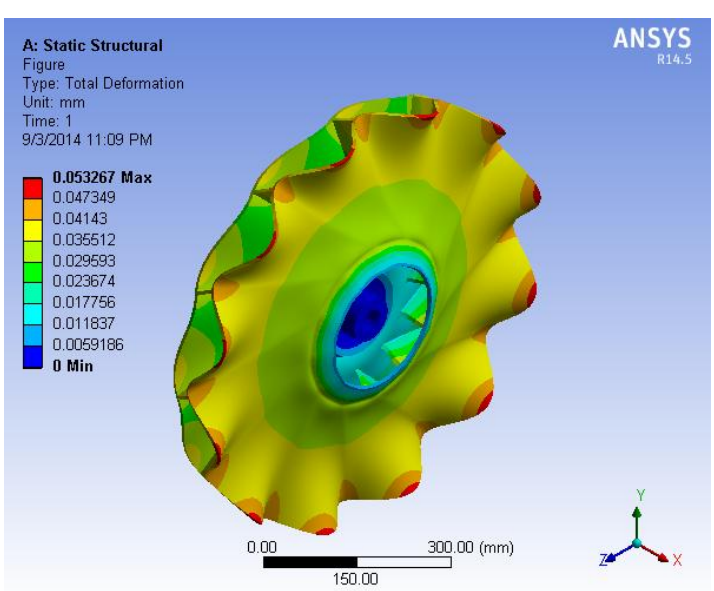

Fig.13 Total deformation of blower impeller (aluminium) 


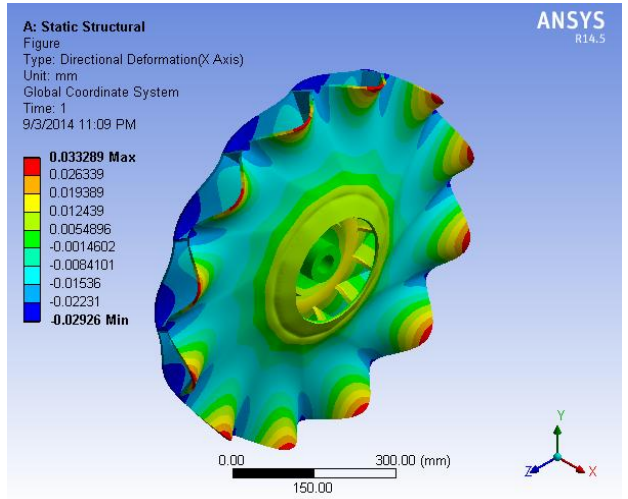

Fig.14 Directional deformation (x-axis) of blower impeller (aluminium)

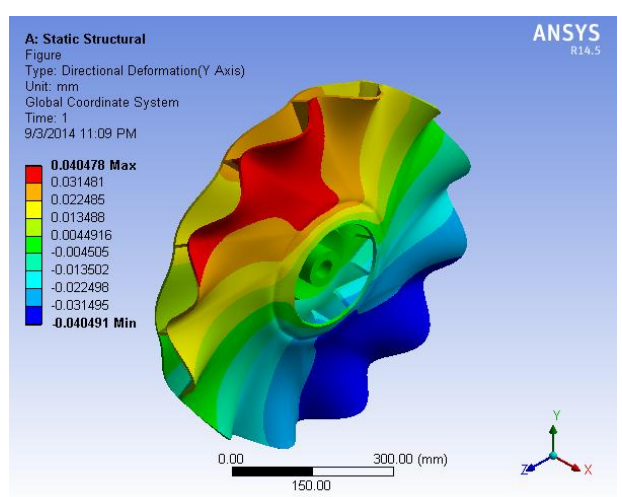

Fig.15 Directional deformation (y-axis) of blower impeller (aluminium)

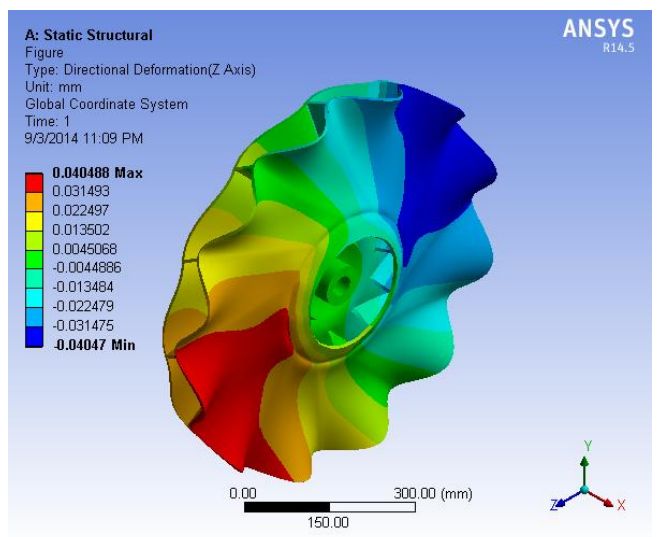

Fig.16 Directional deformation (z-axis) of blower impeller (aluminium)

\begin{tabular}{|l|l|}
\hline Mode & Frequency $[\mathrm{Hz}]$ \\
\hline 1. & 123.61 \\
\hline 2. & 123.71 \\
\hline 3. & 318.36 \\
\hline 4. & 401.37 \\
\hline 5. & 415.01 \\
\hline 6. & 415.09 \\
\hline 7. & 697.06 \\
\hline
\end{tabular}

Fig.17 Prestressed natural frequency of blower impeller (aluminium)

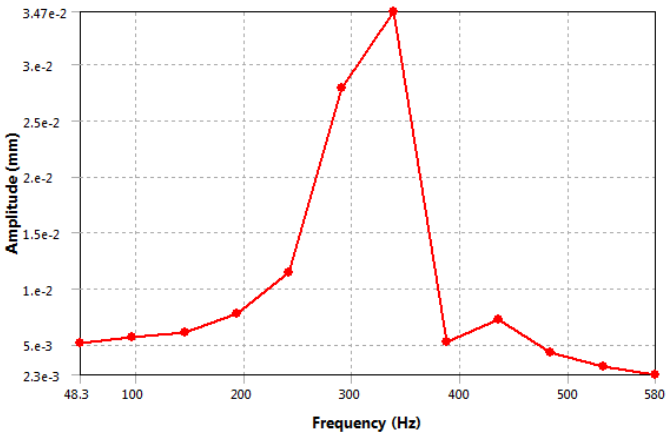

Fig. 18 Deformational Amplitude (x axis) V/s Frequency of aluminium Impeller

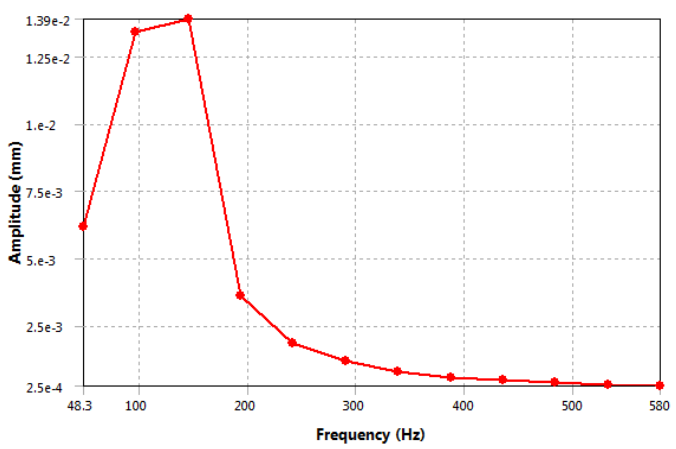

Fig. 19 Deformational Amplitude (y axis) V/s Frequency of aluminium Impeller

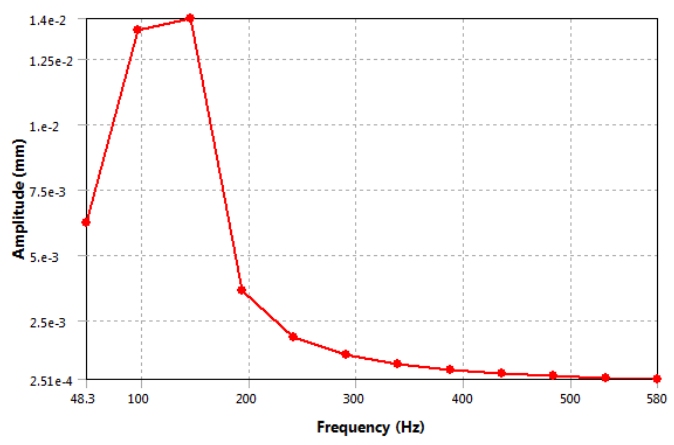

Fig. 20 Deformational Amplitude (z axis) V/s Frequency of aluminium Impeller

\subsection{Composite (Glass/Epoxy):}

Material Properties

\begin{tabular}{|l|l|}
\hline Density $\left(\mathrm{kg} / \mathrm{m}^{3}\right)$ & 1750 \\
\hline Poisson's ratio (xy) & 0.13 \\
\hline Poisson's ratio (yz) & 0.39 \\
\hline Poisson's ratio (zx) & 0.39 \\
\hline Young's modulus (x) (Gpa) & 14 \\
\hline Young's modulus (y) (Gpa) & 14 \\
\hline Young's modulus (z) (Gpa) & 8.8 \\
\hline Shear modulus (xy) (Gpa) & 4.7 \\
\hline Shear modulus (yz) (Gpa) & 4.2 \\
\hline Shear modulus (zx) (Gpa) & 4.2 \\
\hline Constant damping coefficient & 0.02 \\
\hline
\end{tabular}




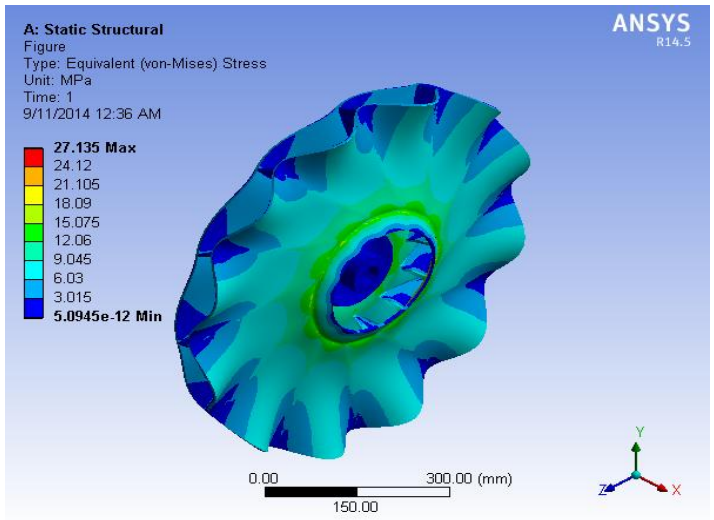

Fig.21 Equivalent (von-mises) stress of blower impeller (glass/epoxy)

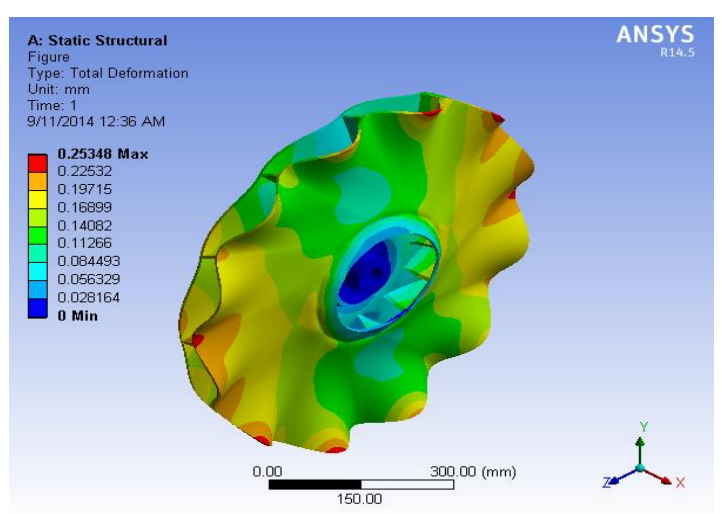

Fig.22 Total deformation of blower impeller (glass/epoxy)

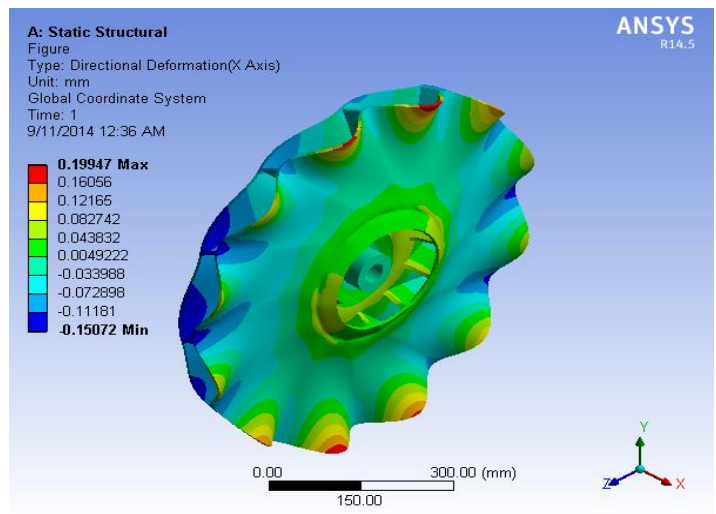

Fig.23 Directional deformation (x-axis) of blower impeller

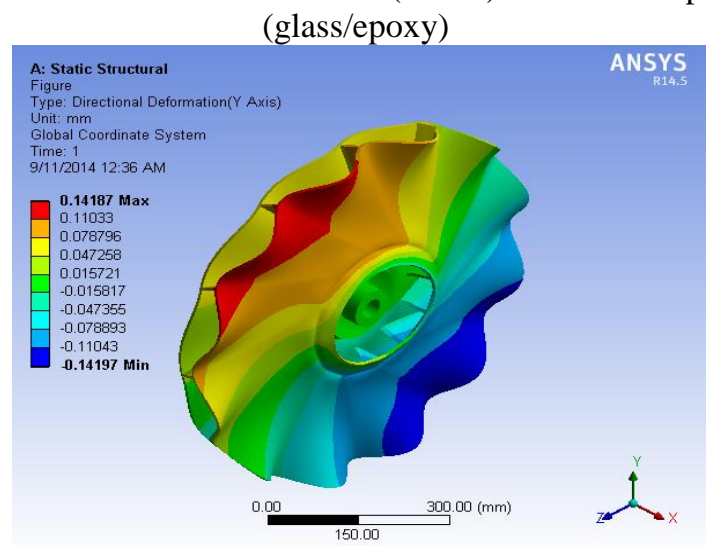

Fig.24 Directional deformation (y-axis) of blower impeller (glass/epoxy)

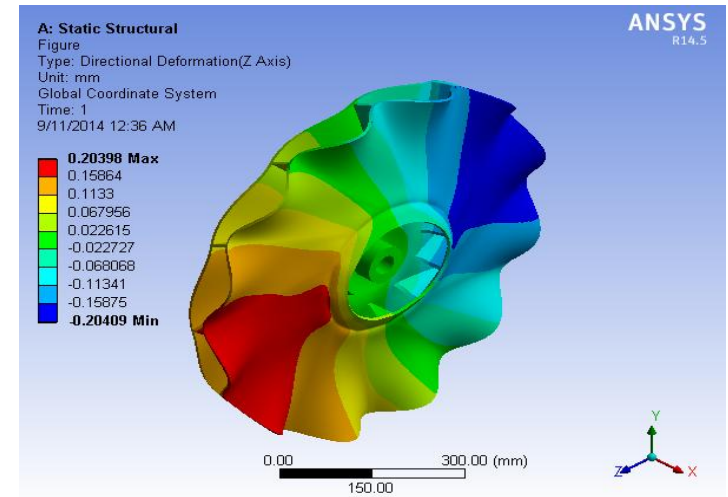

Fig.25 Directional deformation (z-axis) of blower impeller (glass/epoxy)

\begin{tabular}{|l|l|}
\hline Mode & Frequency $[\mathrm{Hz}]$ \\
\hline 1. & 75.157 \\
\hline 2. & 76.525 \\
\hline 3. & 161.71 \\
\hline 4. & 201.31 \\
\hline 5. & 218.86 \\
\hline 6. & 220.93 \\
\hline 7. & 364.72 \\
\hline
\end{tabular}

Fig.26 Prestressed natural frequency of blower impeller (glass/epoxy)

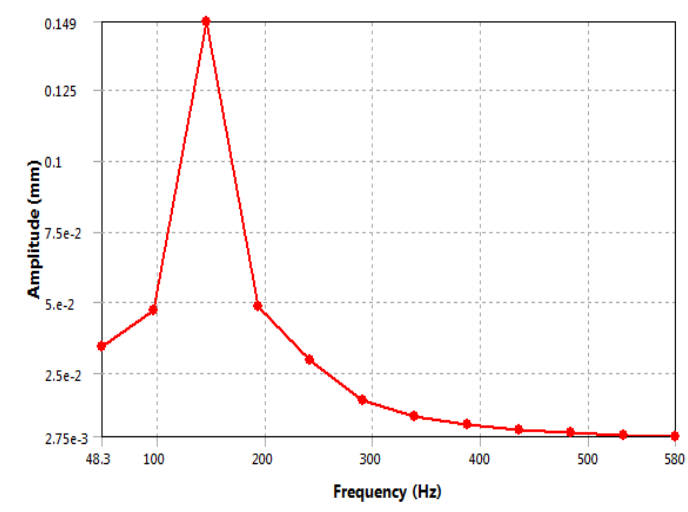

Fig. 27 Deformational Amplitude (x axis) V/s Frequency of glass/epoxy Impeller

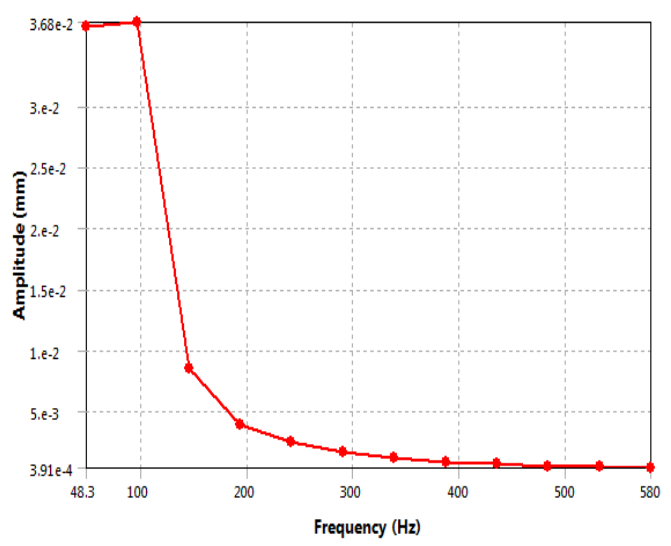

Fig. 28 Deformational Amplitude (y axis) V/s Frequency of glass/epoxy Impeller 


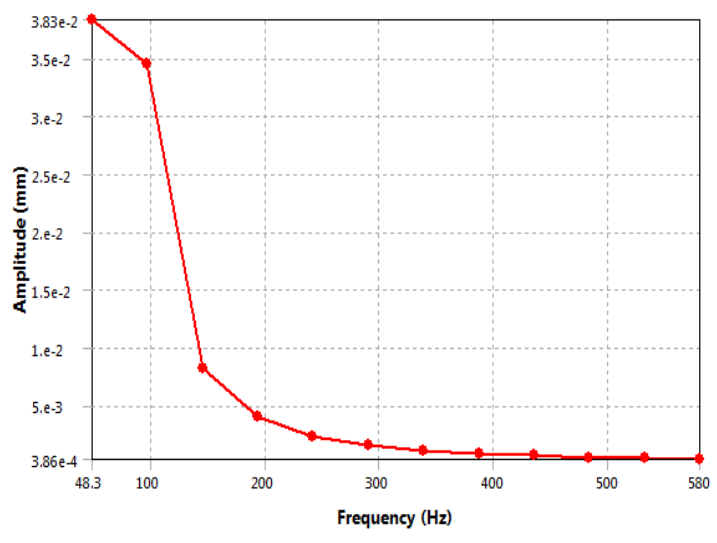

Fig. 29 Deformational Amplitude (z axis) V/s Frequency of glass/epoxy Impeller

Table 1 Result from Analysis

\begin{tabular}{|c|c|c|c|}
\hline $\begin{array}{l}\text { Parameter } \\
\text { Material }\end{array}$ & Steel & Aluminium & $\begin{array}{l}\text { Glass/ } \\
\text { Epoxy }\end{array}$ \\
\hline Mass (kg) & 31.17 & 12.06 & 07.62 \\
\hline Nodes & 294869 & 294675 & 283951 \\
\hline Elements & 147959 & 147969 & 142684 \\
\hline $\begin{array}{l}\text { Equivalent Stress } \\
(\mathrm{MPa})\end{array}$ & 107.82 & 37.51 & 27.135 \\
\hline $\begin{array}{l}\text { Total Deformation } \\
(\mathrm{mm})\end{array}$ & 0.0551 & 0.0532 & 0.2535 \\
\hline $\begin{array}{l}\mathrm{X} \text {-axis deformation } \\
(\mathrm{mm})\end{array}$ & 0.03481 & 0.03328 & 0.19947 \\
\hline $\begin{array}{l}\text { y-axis deformation } \\
(\mathrm{mm})\end{array}$ & 0.04171 & 0.04047 & 0.14187 \\
\hline $\begin{array}{l}\text { z-axis deformation } \\
(\mathrm{mm})\end{array}$ & 0.04167 & 0.04048 & 0.20398 \\
\hline Mode number & \multicolumn{3}{|c|}{ Prestressed natural frequency } \\
\hline 1 & 122.3 & 123.61 & 75.157 \\
\hline 2 & 122.36 & 123.71 & 76.525 \\
\hline 3 & 314.95 & 318.36 & 161.71 \\
\hline 4 & 403.88 & 401.37 & 201.31 \\
\hline 5 & 414.66 & 415.01 & 218.86 \\
\hline 6 & 414.73 & 415.09 & 220.93 \\
\hline 7 & 696.07 & 697.06 & 364.72 \\
\hline $\begin{array}{ll}\mathrm{x} \text {-axis } & \text { amplitude } \\
\mathrm{v} / \mathrm{s} & \text { frequency } \\
(\mathrm{mm}) & \\
\end{array}$ & 0.01133 & 0.03472 & 0.14873 \\
\hline $\begin{array}{ll}\text { y-axis } & \text { amplitude } \\
\mathrm{v} / \mathrm{s} & \text { frequency } \\
(\mathrm{mm}) & \\
\end{array}$ & 0.00498 & 0.013905 & 0.03684 \\
\hline $\begin{array}{ll}\text { z-axis } & \text { amplitude } \\
\mathrm{v} / \mathrm{s} & \text { frequency } \\
(\mathrm{mm}) & \\
\end{array}$ & 0.00505 & 0.01405 & 0.03832 \\
\hline
\end{tabular}

\section{DISCUSSION AND CONCLUSIONS}

1. Mass of the impeller, keeping same thickness of impeller components decreases in the sequence of steel, aluminium and glass/epoxy due to density.

2. Equivalent stress is least for glass/epoxy, less for aluminum and high for steel.

3. Total and directional deformation for aluminum is slightly less than steel.
4. Total and directional deformation for glass/epoxy is more as compared to steel and aluminium.

5. Prestressed natural frequency for steel and aluminum is almost similar.

6. Prestressed natural frequency for glass/epoxy is far low as compared to steel and aluminum.

7. Axial ( $\mathrm{x}, \mathrm{y}$, and $\mathrm{z}$ ) deformational amplitude versus frequency is high for glass/epoxy, less for aluminium and least for steel.

\section{FUTURE SCOPE OF WORK}

In future scope for work, the fan can be simultaneously designed by simulation checking for both flow and structural performance. Also now-a- days materials like aluminium and GRPF (materials) are replacing structural steel as these can be thought of as alternative, unless proving their reliability.

\section{ACKNOWLEDGMENTS}

The satisfaction and exhilaration that accompany the successful completion of any task would be incomplete without the mention of the people whose constant guidance and encouragement aided in its completion. The authors would like to express the voice of gratitude and respect to all who had directly or indirectly supported for carrying out this study and special thanks to Prof.P.D.Darade, Asst. Prof., Mechanical Dept., SITS, Narhe, Staff of mechanical department, Prof.V.R.Bajaj, HOD, Mechanical department and Dr.S.B.Padwal, Principal, Alard College of Engineering and Management, Pune.

\section{REFERENCES}

[1] Engineering Data, Twin City Fan Companies Ltd., ED-200,pp.1-6,1999

[2] Asad Said Juma, Al Zadjali and G.R. Rameshkumar." Condition Monitoring of Centrifugal Blower Using Vibration Analysis", International Journal of Multidisciplinary Sciences, and Engineering, vol.4, no.5, pp.50-59, June 2013.

[3] Shaoping Zhou, Jie Zhang, Yongsheng Su." Vibration analysis and fault diagnosis of the fan unit and support structure." Journal of Pressure Equipment and Systems vol.6, pp.45-48, 2008.

[4] Donald R. Smith, Harold R.Simmons." Unique Fan Vibration Problems: Their Causes and Solutions". Proceedings of the Ninth Turbomachinery Symposium, pp.33-43.

[5] Frantisek L. Eisinger, Robert E. Sullivan." Vibration Fatigue OF Centrifugal Fan Impeller Due TO Structural-Acoustic Coupling and Its Prevention: A CASE Study". Journal of Pressure Vessel Technology, Vol.129, pp.771- 774, November2007.

[6] Robert J. Sayer, "Structural Dynamics of Centrifugal Fans". Proceedings of the National Technical Training Symposium and 34th Annual Meeting of the Vibration Institute, Oak Brook, IL, June 2010.

[7] Robert J. Sayer, "Dynamic Testing Of Centrifugal Fan Wheels ". Proceedings of the National Technical Training Symposium and 34th Annual Meeting of the 
Vibration Institute, Oak Brook, IL, June 2010.

[8] Juan Gabriel Monge Gapper." Centrifugal Fan Impeller Failure Analysis Using Finite Elements". Ingeniería 16 (2): ISSN: 1409-2441; San José, Costa Rica, pp.55-62, 2006.

[9] Veeranjaneyulu Itha, T.B.S.Rao, "Static And Dynamic Analysis Of A Centrifugal Blower Using FEA". International Journal Of Engineering Research And Technology (IJERT) ISSN: 22780181.vol.1,issue.8,pp.1-11,October2012

[10] Mohd Zubair, Ramavath Suman, M.Guru Bramhananda Reddy." Evaluation of Static and Dynamic Analysis Of a Centrifugal Blower Using FEA". International Journal of Advanced Trends in Computer Science and Engineering ISSN: 22783091, .vol.2, no.8, pp.316- 321, January 2013.

[11] S.T. (Ted) Myrick. W.Barry Crawford, Gerald L. Schumpert., "Changing and Controlling the First Critical Speed of Overhung Centrifugal Fans". Proceedings of the Ninth Turbomachinery Symposium, pp.33-40.2004.

[12] P.Mazeika, J.Grigonience, A.Senulis." Influence of Foundation Stiffness on Vibrations Of rotor Systems", Ultragarsas ISSN1392-2114, vol.64, no.2, pp.27-31.2009.

[13] A. El-Shafei." Fan Diagnosis in the Field", RITEC, Cairo, Egypt 2008

[14] Frank P. Bleier,"Fan Handbook-Selection, Application, and Design"ISBN 0-07005933.McGraw-Hill publication.1998. 